\title{
Hyposplenism and Gastrointestinal Diseases: Significance and Mechanisms
}

\author{
Abhinav Mathur ${ }^{\mathrm{a}}$ Mairi H. McLean ${ }^{\mathrm{b}}$ Huan Cao $^{\mathrm{a}}$ Mark A. Vickers ${ }^{\mathrm{a}}$ \\ anfection, Immunity and Inflammation, Institute of Medical Sciences, University of Aberdeen, Aberdeen, UK; \\ ${ }^{b}$ Division of Molecular and Cellular Medicine, School of Medicine, University of Dundee, Dundee, UK
}

\section{Keywords \\ Hyposplenism · Spleen · Coeliac disease · Inflammatory bowel disease}

\begin{abstract}
Background: Functional hyposplenism is a recognized complication of several gastroenterological disorders, including coeliac and inflammatory bowel diseases, and is believed to contribute to the increased infection risk seen in these disorders. Summary: The mechanisms of hyposplenism are poorly understood. In this article, we review possible mechanisms underlying development of functional hyposplenism and discuss implications for its management. Key Messages: Identifying functional hyposplenism is important, as it may permit earlier recognition and treatment of serious infections through patient education and vaccination.
\end{abstract}

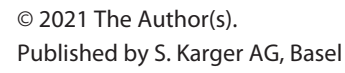

\section{Introduction}

Historically, the spleen has been variably regarded as the seat of compassion, melancholia, laughter, or anger. It was then deemed unnecessary for life once splenectomy started being performed as a surgical procedure in the 1800s [1]. However, it was not until the mid-20th century that the long-term risks of splenectomy became evident, and the true significance of the spleen began to be understood [1]. It is now established that the spleen plays a vital role in filtering and immunological processes, failure of which are thought to underlie the main hazard of asplenia: bacterial infections, notably overwhelming postsplenectomy infection (Box 1). The relative risk of significant infections in splenectomized patients compared to matched controls is 2.0-3.5 [2], with an absolute risk of $0.5 \%$ per year [3]. Although the rates are highest immediately after splenectomy, infections can occur up to 20 years later $[4,5]$. Asplenia can also lead to venous, and possibly arterial, thromboembolic events [6] and has also been associated with higher rates of certain malignancies, although a causal link has yet to be established [2].

Box 1. Overwhelming post-splenectomy infection

Overwhelming post-splenectomy infection is a syndrome of fulminating sepsis characterized by a marked bacteraemia, usually with encapsulated organisms such as Streptococcus pneumoniae or Neisseria meningitidis. There is usually no obvious primary source of infection. Patients present with an acute nonspecific prodrome and can deteriorate rapidly, with death ensuing within 24-48 h. Mortality rates are around 50-70\% [7].

In addition to asplenic states, several diseases have been associated with anatomically intact yet hypofunctional spleens. These include several gastrointestinal disorders (Fig. 1) such as coeliac and inflammatory bowel diseases (IBD) [7]. In this article, we review the
C 2021 The Author(s).

Published by S. Karger AG, Basel

This article is licensed under the Creative Commons Attribution 4.0 International License (CC BY) (http://www.karger.com/Services/ OpenAccessLicense). Usage, derivative works and distribution are permitted provided that proper credit is given to the author and the original publisher.
Correspondence to:

Abhinav Mathur, abhinav.mathur@nhs.scot 


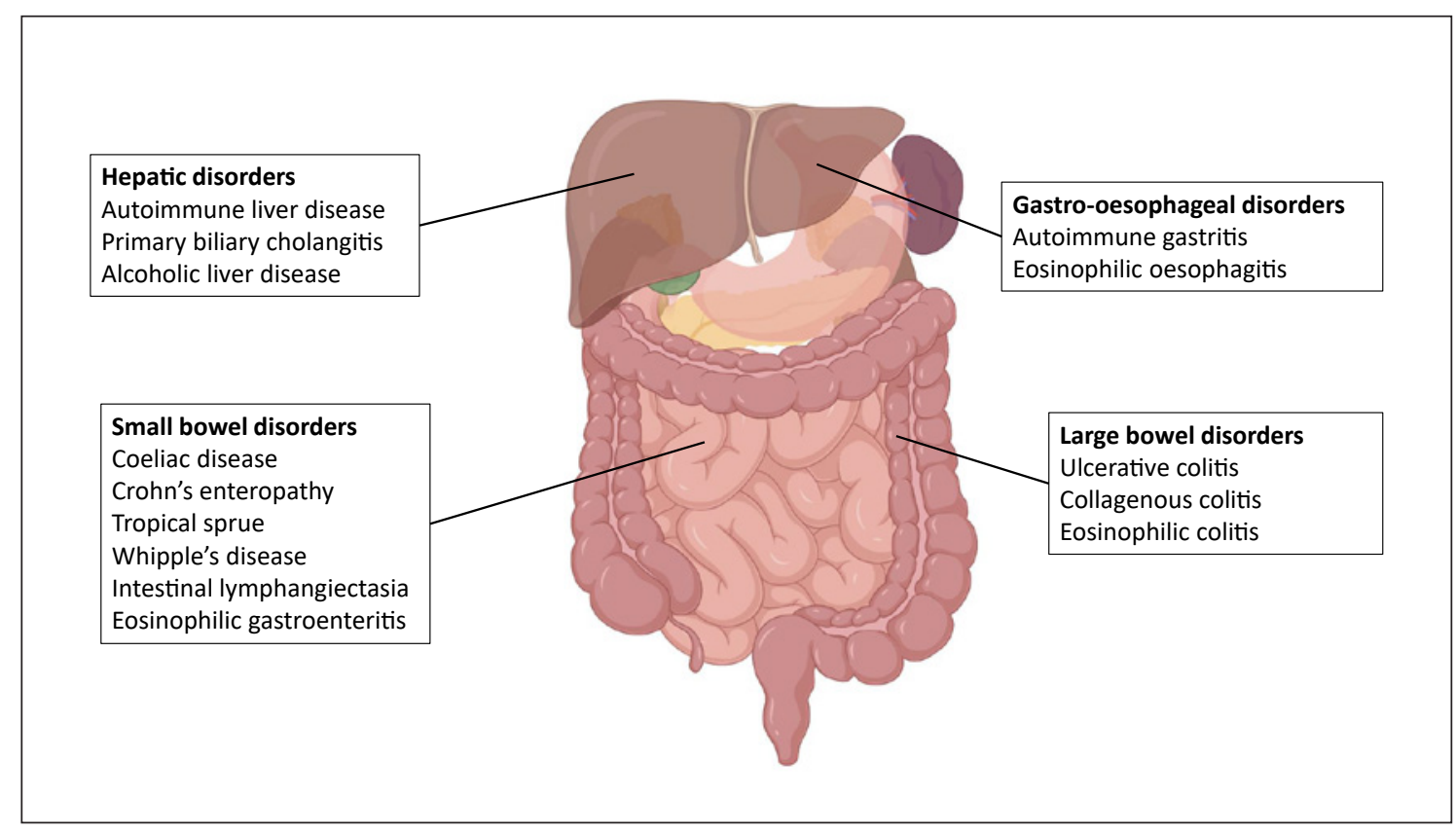

Fig. 1. Range of gastroenterological and hepatic disorders associated with functional hyposplenism. Created with BioRender.com.

evidence for functional hyposplenism in bowel diseases and its clinical significance. We also discuss the possible underlying mechanisms and implications for management.

\section{Coeliac Disease}

Coeliac disease (Box 2) is the gastrointestinal disorder most frequently associated with functional hyposplenism [7]. The prevalence of hyposplenism depends on the diagnostic tests used but is generally lower in paediatrics than adults $[8,9]$. Functional hyposplenism is more common in coeliac disease with complications[10-12]: in one study, it was found in $59 \%$ with associated autoimmune diseases and in $80 \%$ with enteropathy-associated T-cell lymphoma and ulcerative jejunoileitis, but in only $19 \%$ of uncomplicated adult coeliac patients [13]. These findings were supported by a recent study that reported prevalences of functional hyposplenism in patients with untreated (43.7\%) and refractory (88.2\%) coeliac disease [14]. Duration of pre-exposure to gluten and older age at diagnosis were identified as prognostic variables for functional hyposplenism in a multivariate analysis [15].

Hyposplenism and Bowel Diseases
Box 2 Coeliac disease terminology (adapted from references [10-12])

- Classical: coeliac disease with signs and symptoms of malabsorption.

- Paediatric classical: paediatric equivalent of classical coeliac disease.

- Non-classical: coeliac disease without signs and symptoms of malabsorption but other features such as anaemia.

- Refractory coeliac disease (RCD): persistent symptoms and villous atrophy despite a strict gluten-free diet for $>12$ months. It is subclassified as RCD1 (increased phenotypically normal intra-epithelial T lymphocytes) and RCD2 (increased phenotypically abnormal intra-epithelial T lymphocytes).

- Ulcerative jejunoileitis: premalignant small bowel ulcerative disorder that can cause strictures. This shares immunological features with RCD2.

- Enteropathy-associated T-cell lymphoma: a T-cell bowel lymphoma associated with accumulation of abnormal, clonal, intra-epithelial lymphocytes, the most feared complication of coeliac disease.

Three recent large studies have highlighted the potential significance of functional hyposplenism in coeliac disease. Ludvigsson and colleagues [16] used Swedish national health registers to assess the long-term risks of $>15,000$ coeliac patients. They reported significantly higher risks of sepsis, particularly from S. pneumoniae, in coeliac patients compared to both an inpatient reference group and the general population [16]. The relative risk 
of sepsis in coeliac disease (2.6) was higher than that of more commonly recognized complications such as fractures (1.5) [17]. Similar data were reported by Thomas [18] and Röckert Tjernberg [19] and supported by a recent meta-analysis [20].

The increased risk of infection in coeliac disease is likely multifactorial. Causes might include increased gut permeability allowing bacterial translocation and associated diseases that predispose to infections such as type 1 diabetes mellitus [17]. Nevertheless, the observation that infections with encapsulated bacteria, like S. pneumoniae, are particularly common in these patients indicates that hyposplenism plays an important role. How hyposplenism causes susceptibility to these pathogens is still not fully understood. One potential mechanism involves defective splenic reticuloendothelial cells, which fail to entrap circulating pathogens. The spleen is also important in generating and maintaining IgM memory B lymphocytes [21], which produce natural IgM antibodies against carbohydrate antigens, including those with anti-pneumococcal specificity [22].

It is thought that hyposplenism in coeliac disease is the result of 2 distinct mechanisms: functional hyposplenism and splenic atrophy. Evidence to support these distinct mechanisms comes from the association between splenic atrophy and mesenteric lymph node cavitation (MLNC) syndrome. MLNC occurs in advanced coeliac disease and indicates a poor prognosis [23]. Major infections have been reported in several case reports and small series of coeliac patients, variably associated with splenic atrophy and MLNC [24]. In addition, studies have shown that gluten-free diets can reverse functional hyposplenism but not splenic atrophy [25-27]. Notably, different assays for detecting functional hyposplenism were used in these studies - namely, erythrocyte pitting versus heat-damaged erythrocyte uptake - making direct comparisons challenging.

\section{Inflammatory Bowel Disease}

The prevalence of hyposplenism reported in IBD depends on the splenic function test used, but rates of $30 \%$ in ulcerative colitis (UC) and 26\% in Crohn's disease were claimed in early series using blood films and splenic scans [28-30]. Using pitted erythrocyte counting, subsequent studies reported rates of 9\% in Crohn's disease and 20\% in UC [31], while a more recent prevalence study, also using pitted erythrocytes, found functional hyposplenism in around 54\% of UC patients [14].
Patients with IBD are significantly more likely to develop opportunistic infections. One recent American study of around 280,000 IBD patients found the prevalence of opportunistic infections to be $17.8 \%$ in Crohn's disease and $19.2 \%$ in UC compared to $7 \%$ in non-IBD controls [32]. These increased infection rates are likely a reflection of several interacting factors including the use of immunosuppressive medication [33], malnutrition, increased gut permeability, chronic inflammation, and comorbidities [34]. However, recent data have highlighted the potential importance of functional hyposplenism in IBD as another cause of these increased infection rates.

A Danish study of 74,156 IBD patients reported a significantly increased risk of invasive pneumococcal disease in patients with IBD [35]. This propensity for infections with encapsulated bacteria suggests that hyposplenism is an important contributing factor. Importantly, based on conditional logistic regression, the risk of invasive pneumococcal disease was deemed unrelated to the underlying IBD medications and was present up to 4 years before diagnosis $[35,36]$. Similarly, Goren and colleagues [37] analysed the rates of bacteraemia in hospitalized patients with IBD. Using logistic regression modelling, they found age, and not IBD-related medications, to be associated with increased rates of bacteraemia.

Strategies to normalize this infection risk have been assessed through effects on putative mechanisms of predisposition. In a study of $61 \mathrm{IBD}$ patients, a depletion of peripheral IgM memory B lymphocytes, important in the immune response to encapsulated bacteria, correlated with splenic impairment assessed by pitted erythrocyte counts [38]. Treatment with infliximab, an anti-tumour necrosis factor alpha (TNFa) monoclonal antibody, restored this pool of lymphocytes and splenic function in the majority of Crohn's patients [39]. It is of interest to note that a multivariate analysis of Crohn's patients found that the increased risk of infections in patients on infliximab is related to disease severity and use of prednisolone [40], rather than infliximab itself.

Hyposplenic IBD patients may also be at risk of other complications such as post-operative pneumococcal sepsis, septic shock, and disseminated intravascular coagulation $[30,41]$. Smaller spleen length at the time of surgery correlated with more aggressive IBD and complications such as perforation, fistulas, abscesses, and bleeding in an early case series of 116 patients [42]. Furthermore, IBD patients are at increased risk of thrombosis, and treatment guidelines advise prophylactic anticoagulation [43]. This prothrombotic and hypercoagulable state in IBD is thought to be secondary to active inflammation [44] and one that splenic dysfunction may well contribute to. One study reports a case of 
Table 1. Proposed mechanisms of hyposplenism in bowel diseases

\begin{tabular}{ll}
\hline $\begin{array}{l}\text { Proposed mechanism } \\
\begin{array}{l}\text { Reticuloendothelial } \\
\text { atrophy }\end{array}\end{array}$ & $\begin{array}{l}\text { A quantitative splenic function defect consisting of disrupted splenic lymphocyte recirculation likely } \\
\text { secondary to intestinal lymphocyte egress }\end{array}$ \\
\hline $\begin{array}{l}\text { Splenic atrophy } \\
\text { A quantitative splenic function defect linked to immune dysfunction. In coeliac disease, the marginal zone } \\
\text { and white pulp B-lymphocyte compartments are depleted }\end{array}$ \\
$\begin{array}{l}\text { Reticuloendothelial } \\
\text { blockade }\end{array}$ & $\begin{array}{l}\text { Disruption of splenic function by circulating substances such as complement-binding immune complexes or } \\
\text { pathogens that limit binding of other substances leading to reduced splenic activity }\end{array}$ \\
\hline
\end{tabular}

ischaemic stroke in a patient with Crohn's disease associated with splenic atrophy [45], suggesting that hyposplenism may be contributory to the thrombotic risk in IBD. Studies assessing spleen size and function in IBD patients with or without thrombotic complications are awaited.

\section{Other Gastrointestinal Disorders}

Case reports have demonstrated features of hyposplenism in various malabsorptive and inflammatory bowel disorders including tropical sprue, Whipple's disease, eosinophilic gastroenterological disorders, collagenous colitis, and intestinal lymphangiectasia [46-50] and in various hepatic disorders [7]. The extent and significance of hyposplenism in these bowel disorders have not been extensively studied. A recent study, although limited by small numbers, also reported a high prevalence of hyposplenism in various autoimmune gastrointestinal disorders including autoimmune atrophic gastritis (55\%), autoimmune enteropathy (66.6\%), and autoimmune liver disease (87.5\%) [14].

\section{Mechanisms of Hyposplenism in Bowel Disease}

The aetiology of hyposplenism in bowel diseases remains largely unknown, but several theories exist (Table 1; Fig. 2). A better understanding of these mechanisms might permit rational therapeutic approaches to optimize splenic function and minimize infection risk.

\section{Reticuloendothelial Atrophy}

Immune defects in hyposplenism may be quantitative rather than reflecting a specific defective splenic function. Hyposplenic individuals have less lymphoid tissue than control subjects [51]. Lymphocyte depletion from thoracic duct drainage in animals leads to splenic appear- ances similar to those seen in coeliac disease [52]. In digestive disorders, lymphocyte depletion may occur through the enteric route [53], potentially disrupting lymphocyte recirculation within the spleen and subsequent reticuloendothelial atrophy. However, this theory has not been fully supported experimentally [54]. Splenic immune cell egress may also occur after intestinal manipulation (e.g., laparotomy) [55]. Whether this can also cause hyposplenism is yet to be assessed, and effects are likely short lived and limited to the peri-operative period.

In experimental murine models of Leishmania donovani infection, TNFa was particularly important in lymphocyte traffic and splenic marginal zone remodelling [56]. Mice that lacked TNFa, or those mice that received anti-TNFa antibodies, had preserved marginal zone macrophages. In one study, patients with Crohn's disease given infliximab restored their pool of peripheral IgM memory B lymphocytes [39]. There has been no study assessing whether restoration of this pool of lymphocytes reduces the rates of infection in patients with gastrointestinal diseases. However, reduction in IgM memory B lymphocytes after splenectomy was not associated with increased rates of infection [57].

\section{Splenic Atrophy}

Another quantitative defect that may contribute to hyposplenism is splenic atrophy. While splenic atrophy in sickle cell disease is thought to occur through multiple episodes of splenic infarctions [58], the mechanisms of splenic atrophy in gastrointestinal disorders remain poorly understood. The suggestion that an autoimmune process is important is supported by the various immunological abnormalities demonstrated in splenic atrophy $[59,60]$. Further evidence for an autoimmune aetiology in splenic atrophy comes from a study of chronic lymphocytic choriomeningitis virus clone 13 (LCMV13) infection in mice [61]. While acute LCMV13 infection leads to a 


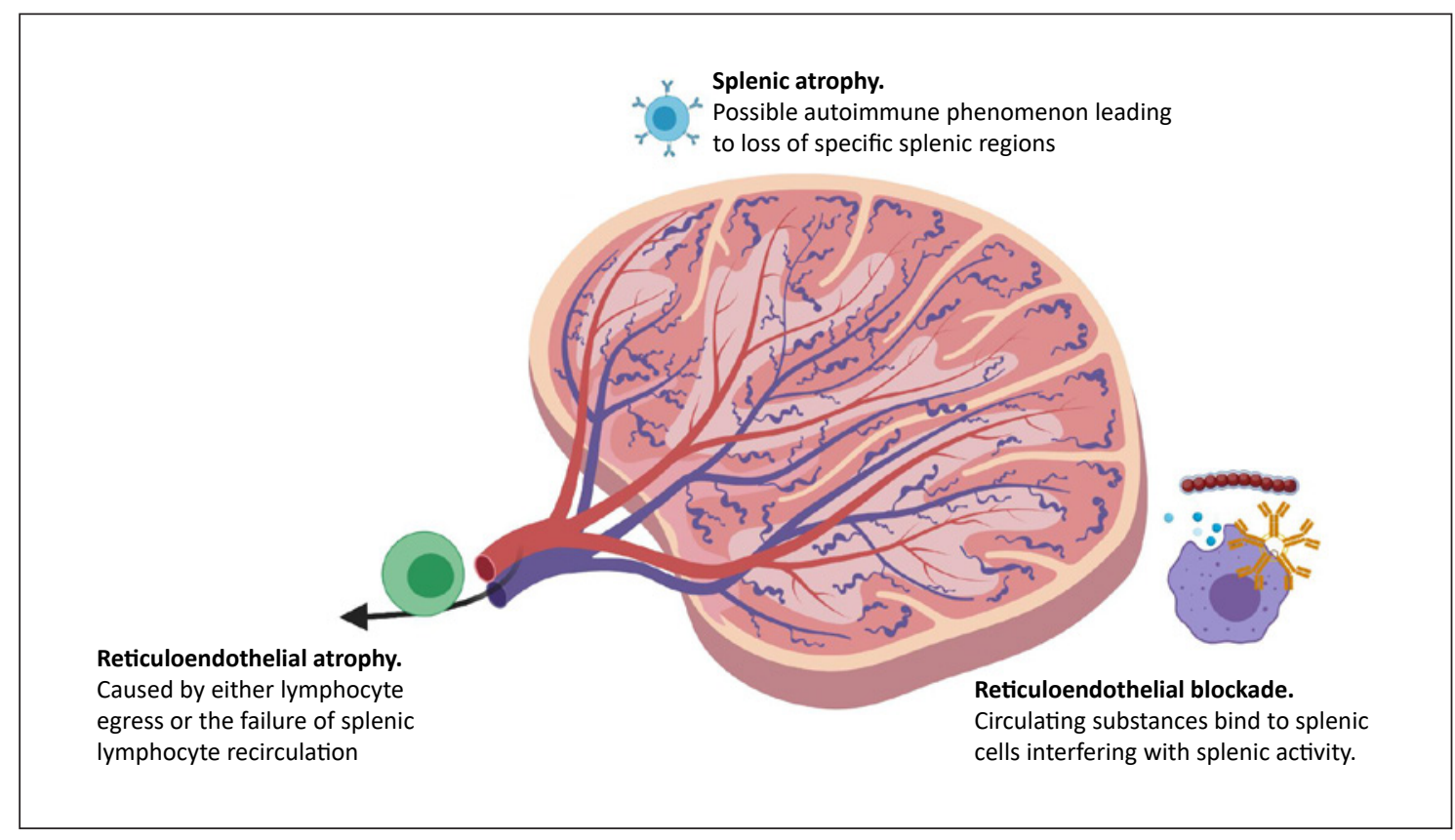

Fig. 2. Proposed mechanisms underlying hyposplenism in bowel disorders. Created with BioRender.com.

temporary disruption of splenic architecture, chronic LCMV13 infection leads to irreversible splenic atrophy with predominant loss of B lymphocytes [61]. The authors demonstrated that $\mathrm{NK} 1.1^{+}$and $\mathrm{CD}^{+}$cells were at least partly responsible for this splenic atrophy and that inhibiting these cells mitigated some of the destruction [61]. Splenic atrophy can occur in coeliac disease and specifically affects the size of the marginal zone and white pulp B-lymphocyte compartment [62], possibly via an autoimmune mechanism. This could lead to IgM memory B-lymphocyte depletion and contribute to hyposplenism.

\section{Reticuloendothelial Block}

The reticuloendothelial function of the spleen may be blocked by circulating substances such as immune complexes or pathogens. For example, functional hyposplenism in rheumatoid arthritis can occur secondary to circulating immune complexes interfering with reticuloendothelial function [63]. Plasma exchange can reverse impaired splenic function in patients with nephritis and vasculitis by removing circulating complement-binding immune complexes [64]. There is evidence for raised levels of complement-binding immune complexes in coeliac disease and IBD [65], but whether these reduce splenic function is unclear [54].

Damage to the intestinal barrier may also be important and perhaps explains why many different gastrointestinal disorders are associated with hyposplenism. A dysfunctional intestinal barrier results in increased permeability and translocation of bacteria and bacterial products into the systemic circulation [66]. Subsequent splenic uptake [67] may cause a reticuloendothelial block leading to hyposplenism. This also suggests that controlling the underlying bowel disease may ameliorate hyposplenism. In keeping with this, mice treated with probiotics attenuated gut permeability and reduced splenic pro-inflammatory cytokine production [68]. Although not specifically assessed, treatment of Crohn's patients with infliximab improved splenic function [39].

Emerging research suggests that gut microbiota influences many areas of human health and disease [69]. Notably, development of the spleen is modulated by gut microbiota diversity. Rosado and colleagues [70] demonstrated that gut colonization within the first 2 weeks of life promotes the development of secondary lymphoid structures and expands B-lymphocyte compartments within the spleen. A subtype of splenic IgM-expressing B lymphocyte is important in generating IgA responses in the gut [71]. Recent work demonstrates that spleen-associated IgM B lymphocytes may migrate to the gut to generate localized secretory IgA mucosal immune responses [72]. Reduction in IgM memory B lymphocytes in hyposplenic patients may therefore lead to reduced local IgA responses and increased susceptibility to infection. Al- 
though unproven, an altered gut microbiome in bowel disorders may also influence the maintenance of these lymphocytes and contribute toward splenic dysfunction.

\section{Investigating Hyposplenism}

Mammalian spleens have 2 main structural elements, white and red pulp, corresponding to the 2 main functions of the spleen. The white pulp is concerned with adaptive immune responses against blood-borne antigens. Despite extensive knowledge of these immune responses [73], none are yet characteristic or measurable enough to be considered tests of splenic function. For example, while splenic function is inversely correlated with circulating IgM memory B lymphocytes in coeliac disease [13] and IBD [38], measurement of this immunological biomarker has not been validated in clinical practice. The red pulp acts as a filter for blood - mechanically through venous slits and physiologically via phagocytic activity removing infectious agents, colloidal particles, effete red cells, and platelets. In addition to the removal of whole cells, it also has an "editing" function, whereby oxidatively damaged membranes are removed from erythrocytes.

Apart from direct splenic imaging, all current "splenic function tests" are measures of red cell clearance or editing. Most techniques are not routinely available outside research settings or are not sensitive enough to be used as screening tests in clinical practice. Thus, identifying functional hyposplenism is challenging, and a robust and easily applied test remains an unmet need.

The original method of assessing hyposplenism relied on counting Howell-Jolly bodies (basophilic red blood cell inclusions) on peripheral blood smears [58]. Although simple, repeatable, and widely available, it was not sensitive enough to detect milder degrees of hyposplenism [74]. One recent prospective study demonstrated that detection of Howell-Jolly bodies may be used as an initial screening test for functional hyposplenism [75]. Scintigraphic methods were developed to assess splenic function by monitoring the rate of clearance of technetium-99 m-labelled substances or heat-damaged, autologous erythrocytes [76]. These methods can be combined with imaging tools to allow a reliable and simultaneous assessment of spleen function and volume. However, they are time consuming, expose patients to radiation, and are not widely available.

The most widespread method for assessing splenic function is counting of "pits" on the surface of erythrocytes using differential interference contrast microscopy [77]. These pits are vacuoles beneath the erythrocyte plas- ma membrane, which are visible as crater-like depressions. A pitted erythrocyte count of $>4 \%$ has been associated with hyposplenism in various conditions, including coeliac disease $[76,78]$. Since counting pits is repeatable, quantitative, and learned through brief training, it has been regarded as the standard for assessing splenic function. The equipment for pit counting is more commonly available in research rather than clinical settings. However, conventional microscopes can be converted into interference phase contrast mode through Nomarski optics in an inexpensive manner. Some experts have suggested that counting pitted erythrocytes could be used to screen patients, who could then undergo scintigraphic scanning to confirm hyposplenism [76].

\section{Management of Hyposplenism}

Hyposplenism is not currently assessed in individuals with gastrointestinal diseases, and there are no specific considerations for management in current guidelines. Testing for hyposplenism through haematological blood analysis should be considered and general management guidelines applied, if there is clinical suspicion. Infection remains the main hazard of hyposplenism, and several strategies of prevention can be employed.

\section{Education and Early Treatment of Infections}

Hyposplenic patients should be identified as being at risk of infection. National guidelines advocate that both patients and healthcare professionals should be educated about these risks so that potentially life-threatening infections can be treated promptly $[79,80]$. Patients should be taught about when to seek medical care and the importance of vaccinations. Increased awareness may be achieved through information leaflets, alert bracelets, and the systematic development of registries. Spleen Australia, a national spleen registry, has recently been shown to significantly reduce the rates of invasive infections in asplenic and hyposplenic patients [81]. Arguably, the main benefit of registries is their educational value, encouraging vaccination and prompting earlier recognition of infections [82]. They also act to identify patients who have not been adequately dealt with by routine clinical care.

\section{Vaccinations}

The British Society of Gastroenterology (BSG) recommends that adults with coeliac disease be vaccinated against S. pneumoniae [83] and that all IBD patients on immunomodulatory or biologic therapies should receive 
pneumococcal vaccination with a booster after 5 years [43]. Unfortunately, the uptake of vaccination is poor. In one large study of at-risk individuals, only $3.7 \%$ of the 3,584 patients with either sickle cell or coeliac disease had been vaccinated in the past 12 months and $13.5 \%$ in the past 5 years [84]. Spleen registries and better patient education may increase uptake.

The choice of vaccine in potentially hyposplenic individuals is important since protection against encapsulated bacteria is dependent on T-independent IgM memory B lymphocytes, which are impaired in hyposplenism. Impaired immune responses to various vaccines have been seen in hyposplenic individuals $[85,86]$. Conjugated vaccines, which elicit T-cell-dependent immune responses, can restore the pool of anti-pneumococcal IgG memory B lymphocytes in asplenic patients [87]. Patients with Crohn's disease developed higher antibody responses to certain pneumococcal serotypes when given the conjugated vaccine [88]. Vaccination strategies tailored to hyposplenic populations should include conjugated vaccines.

The timing of vaccination is another important issue. Immunosuppressive medications impair vaccine responses in IBD patients [88]. Some authors have argued that IBD patients should be vaccinated at the time of diagnosis, rather than prior to initiating immunosuppressive drug regimens [36].

\section{Antibiotics}

The role of antibacterial prophylaxis in hyposplenism remains unclear and is not universally recommended. The evidence supporting use of antibacterial prophylaxis in functional hyposplenism emerges from the sickle cell disease literature, where the associated hyposplenism is more profound than that observed in gastrointestinal diseases. In a meta-analysis evaluating 457 children with sickle cell disease and hyposplenism, daily penicillin prophylaxis reduced the incidence of pneumococcal infection by 3 -fold [89]. The British Society for Haematology guidelines advocate lifelong penicillin prophylaxis in high-risk cases [79].

There is insufficient evidence to support the routine use of antibiotic prophylaxis in hyposplenic patients with bowel disorders. While the possible benefits of preventing severe infections with antibiotic prophylaxis are selfevident, there are potential significant harms to this approach. These include emergence of multi-drug-resistant organisms, especially since adherence to daily antibiotics is poor [90]. Antibiotic exposure can disrupt the symbiotic relationship between host and gut microbiome leading to dysbiosis [91], and microbiota dysbiosis plays a part in the pathogenesis of gastrointestinal diseases. There is a reported association between antibiotic exposure and development of coeliac disease [92] and perhaps even IBD [93]. Finally, adverse drug-related effects such as hypersensitivity can occur.

\section{Conclusions}

Functional hyposplenism is a complication of many gastroenterological disorders, although poorly understood and seldom assessed. There is increasing evidence suggesting that functional hyposplenism contributes to the increased infection risk in patients with coeliac disease and IBD. Although counting pitted erythrocytes can accurately assess splenic function, the test is not routinely used. Infectious complications of functional hyposplenism can be minimized through education and vaccination. However, there is currently insufficient evidence to recommend antibiotic prophylaxis.

\section{Conflict of Interest Statement}

The authors have no conflicts of interest to declare.

\section{Funding Sources}

This work was funded in part by the Wellcome Trust (Grant No. 0934847/Z/10/Z).

\section{Author Contributions}

A.M. wrote the first draft of the manuscript. All authors reviewed and contributed to the writing of the article.

References

1 Wilkins BS. The spleen. Br J Haematol. 2002; 117:265-74.

2 Kristinsson SY, Gridley G, Hoover RN, Check D, Landgren O. Long-term risks after splenectomy among 8,149 cancer-free American veterans: a cohort study with up to 27 years follow-up. Haematologica. 2014;99:392-8.

3 Bisharat N, Omari H, Lavi I, Raz R. Risk of infection and death among post-splenectomy patients. J Infect. 2001;43:182-6.

4 Green JB, Shackford SR, Sise MJ, Fridlund P. Late septic complications in adults following splenectomy for trauma: a prospective analysis in 144 patients. J Trauma. 1986;26:999-1004. 
5 Thomsen RW, Schoonen WM, Farkas DK, Riis A, Jacobsen J, Fryzek JP, et al. Risk for hospital contact with infection in patients with splenectomy: a population-based cohort study. Ann Intern Med. 2009;151:546-55.

6 Crary SE, Buchanan GR. Vascular complications after splenectomy for hematologic disorders. Blood. 2009;114:2861-8.

7 Di Sabatino A, Carsetti R, Corazza GR. Postsplenectomy and hyposplenic states. Lancet. 2011;378:86-97.

8 Marsh GW, Stewart JS. Splenic function in adult coeliac disease. Br J Haematol. 1970;19: $445-57$.

9 Corazza GR, Lazzari R, Frisoni M, Collina A, Gasbarrini G. Splenic function in childhood coeliac disease. Gut. 1982;23:415-6.

10 Di Sabatino A, Biagi F, Gobbi PG, Corazza GR. How I treat enteropathy-associated Tcell lymphoma. Blood. 2012;119:2458-68.

11 Lebwohl B, Sanders DS, Green PHR. Coeliac disease. Lancet. 2018;391(10115):70-81.

12 Ludvigsson JF, Leffler DA, Bai JC, Biagi F, Fasano A, Green PHR, et al. The Oslo definitions for coeliac disease and related terms. Gut. 2013;62:43-52.

13 Di Sabatino A, Rosado MM, Cazzola P, Riboni R, Biagi F, Carsetti R, et al. Splenic hypofunction and the spectrum of autoimmune and malignant complications in celiac disease. Clin Gastroenterol Hepatol. 2006;4: 179-86.

14 Giuffrida P, Aronico N, Rosselli M, Lenti MV, Cococcia S, Roccarina D, et al. Defective spleen function in autoimmune gastrointestinal disorders. Intern Emerg Med. 2020;15: 225-9.

15 Corazza GR, Zoli G, Di Sabatino A, Ciccocioppo R, Gasbarrini G. A reassessment of splenic hypofunction in celiac disease. Am J Gastroenterol. 1999;94:391-7.

16 Ludvigsson JF, Olén O, Bell M, Ekbom A, Montgomery SM. Coeliac disease and risk of sepsis. Gut. 2008;57:1074-80.

17 Walters JR, Bamford KB, Ghosh S. Coeliac disease and the risk of infections. Gut. 2008; 57:1034-5.

18 Thomas HJ, Wotton CJ, Yeates D, Ahmad T, Jewell DP, Goldacre MJ. Pneumococcal infection in patients with coeliac disease. Eur J Gastroenterol Hepatol. 2008;20:624-8.

19 Rockert Tjernberg A, Bonnedahl J, Inghammar M, Egesten A, Kahlmeter G, Nauclér P, et al. Coeliac disease and invasive pneumococcal disease: a population-based cohort study. Epidemiol Infect. 2017;145:1203-9.

20 Simons M, Scott-Sheldon LAJ, Risech-Neyman Y, Moss SF, Ludvigsson JF, Green PHR. Celiac disease and increased risk of pneumococcal infection: a systematic review and meta-analysis. Am J Med. 2018;131:83-9.

21 Kruetzmann S, Rosado MM, Weber H, Germing U, Tournilhac O, Peter HH, et al. Human immunoglobulin $\mathrm{M}$ memory B cells controlling Streptococcus pneumoniae infections are generated in the spleen. J Exp Med. 2003;197: 939-45.
22 Capolunghi F, Cascioli S, Giorda E, Rosado MM, Plebani A, Auriti C, et al. CpG drives human transitional B cells to terminal differentiation and production of natural antibodies. J Immunol. 2008;180:800-8.

23 Freeman HJ. Mesenteric lymph node cavitation syndrome. World J Gastroenterol. 2010; 16:2991-3.

24 Di Sabatino A, Brunetti L, Carnevale Maffè G, Giuffrida P, Corazza GR. Is it worth investigating splenic function in patients with celiac disease? World J Gastroenterol. 2013;19:2313-8.

25 Trewby PN, Chipping PM, Palmer SJ, Roberts PD, Lewis SM, Stewart JS. Splenic atrophy in adult coeliac disease: is it reversible? Gut. 1981;22:628-32.

26 O'Grady JG, Stevens FM, Harding B, O'Gorman TA, McNicholl B, McCarthy CF. Hyposplenism and gluten-sensitive enteropathy. Natural history, incidence, and relationship to diet and small bowel morphology. Gastroenterology. 1984;87:1326-31.

27 Corazza GR, Frisoni M, Vaira D, Gasbarrini G. Effect of gluten-free diet on splenic hypofunction of adult coeliac disease. Gut. 1983; 24:228-30.

28 Ryan FP, Smart R, Preston FE, Holdsworth CD. Hyposplenism in ulcerative colitis. Lancet. 1974;2:318-20

29 Ryan FP, Smart RC, Holdsworth CD, Preston FE. Hyposplenism in inflammatory bowel disease. Gut. 1978;19:50-5.

30 Palmer KR, Sherriff SB, Holdsworth CD, Ryan FP. Further experience of hyposplenism in inflammatory bowel disease. Q J Med. 1981;50:463-71.

31 Muller AF, Cornford E, Toghill PJ. Splenic function in inflammatory bowel disease: assessment by differential interference microscopy and splenic ultrasound. Q J Med. 1993; 86:333-40.

32 Sheriff MZ, Mansoor E, Luther J, Ananthakrishnan AN, Abou Saleh M, Ho E, et al. Opportunistic infections are more prevalent in Crohn's disease and ulcerative colitis: a large population-based study. Inflamm Bowel Dis. 2020;26:291-300.

33 Kirchgesner J, Lemaitre M, Carrat F, Zureik M, Carbonnel F, Dray-Spira R. Risk of serious and opportunistic infections associated with treatment of inflammatory bowel diseases. Gastroenterology. 2018;155:337-46.e10.

34 Lenti MV, Mengoli C, Vernero M, Aronico N, Conti L, Borrelli de Andreis F, et al. Preventing infections by encapsulated bacteria through vaccine prophylaxis in inflammatory bowel disease. Front Immunol. 2020;11:485.

35 Kantso B, Simonsen J, Hoffmann S, Valentiner-Branth P, Petersen AM, Jess T, Inflammatory bowel disease patients are at increased risk of invasive pneumococcal disease: a nationwide danish cohort study 1977-2013. Am J Gastroenterol. 2015;110:1582-7.

36 Cushing KC, Kanuri N, Ciorba MA. Pneumococcal disease in inflammatory bowel disease: justification to vaccinate at diagnosis. Gastroenterology. 2016;151:365-6.
37 Goren I, Brom A, Yanai H, Dagan A, Segal G, Israel A. Risk of bacteremia in hospitalised patients with inflammatory bowel disease: a 9-year cohort study. United European Gastroenterol J. 2019;8:195-203.

38 Di Sabatino A, Rosado MM, Ciccocioppo R, Cazzola P, Morera R, Corazza GR, et al. Depletion of immunoglobulin $\mathrm{M}$ memory B cells is associated with splenic hypofunction in inflammatory bowel disease. Am J Gastroenterol. 2005;100:1788-95.

39 Di Sabatino A, Rosado MM, Cazzola P, Biancheri P, Tinozzi FP, Laera MR, et al. Splenic function and IgM-memory B cells in Crohn's disease patients treated with infliximab. Inflamm Bowel Dis. 2008;14:591-6.

40 Lichtenstein GR, Feagan BG, Cohen RD, Salzberg BA, Diamond RH, Chen DM, et al. Serious infections and mortality in association with therapies for Crohn's disease: TREAT registry. Clin Gastroenterol Hepatol. 2006;4: 621-30.

41 Foster KJ, Devitt N, Gallagher PJ, Abbott RM. Overwhelming pneumococcal septicaemia in a patient with ulcerative colitis and splenic atrophy. Gut. 1982;23:630-2.

42 Pereira JL, Hughes LE, Young HL. Spleen size in patients with inflammatory bowel disease. Does it have any clinical significance? Dis Colon Rectum. 1987;30:403-9.

43 Lamb CA, Kennedy NA, Raine T, Hendy PA, Smith PJ, Limdi JK, et al. British society of gastroenterology consensus guidelines on the management of inflammatory bowel disease in adults. Gut. 2019;68:s1-06.

44 McCurdy JD, Kuenzig ME, Smith G, Spruin S, Murthy SK, Carrier M, et al. Risk of venous thromboembolism after hospital discharge in patients with inflammatory bowel disease: a population-based study. Inflamm Bowel Dis. 2020;26(11):1761-8.

45 Subran B, Salama L, Dreyfus M, Carbonnel F, Besson C. Thrombosis in acquired hyposplenism associated with Crohn disease. Presse Med. 2010;39:726-7.

46 Suarez RM, Spies TD, Suarez RMJr. The use of folic acid in sprue. Ann Intern Med. 1947; 26:643-77.

47 Haeney MR, Ross IN. Whipple's disease in a female with impaired cell-mediated immunity unresponsive to co-trimoxazole and levamisole therapy. Postgrad Med J. 1978;54:45-50.

48 Freeman HJ. Functional asplenia and microscopic (collagenous) colitis. Can J Gastroenterol. 1996;10:443-6.

49 Foster PN, Bullen AW, Robertson DA, Chalmers DM, Losowsky MS. Development of impaired splenic function in intestinal lymphangiectasia. Gut. 1985;26:861-4.

50 Di Sabatino A, Aronico N, Giuffrida P, Cococcia S, Lenti MV, Vanoli A, et al. Association between defective spleen function and primary eosinophilic gastrointestinal disorders. J Allergy Clin Immunol Pract. 2018;6: 1056-8.e1. 
51 McCarthy CF, Fraser ID, Evans KT, Read AE. Lymphoreticular dysfunction in idiopathic steatorrhoea. Gut. 1966;7:140-8.

52 Fish JC, Beathard G, Sarles HE, Remmers AR, Ritzmann SE. Circulating lymphocyte depletion: effect on lymphoid tissue. Surgery. 1970; 67:658-66.

53 Douglas AP, Weetman AP, Haggith JW. The distribution and enteric loss of 51Cr-labelled lymphocytes in normal subjects and in patients with coeliac disease and other disorders of the small intestine. Digestion. 1976;14:2943.

54 Palmer KR, Barber DC, Sherriff SB, Holdsworth CD. Reticuloendothelial function in coeliac disease and ulcerative colitis. Gut. 1983;24:384-8.

55 Costes LM, van der Vliet J, Farro G, Matteoli $\mathrm{G}$, van Bree SH, Olivier BJ, et al. The spleen responds to intestinal manipulation but does not participate in the inflammatory response in a mouse model of postoperative ileus. PLoS One. 2014;9:e102211.

56 Engwerda CR, Ato M, Cotterell SE, Mynott TL, Tschannerl A, Gorak-Stolinska PM, et al. A role for tumor necrosis factor-alpha in remodeling the splenic marginal zone during Leishmania donovani infection. Am J Pathol. 2002;161:429-37.

57 Cameron PU, Jones P, Gorniak M, Dunster K, Paul E, Lewin S, et al. Splenectomy associated changes in IgM memory B cells in an adult spleen registry cohort. PLoS One. 2011;6: e23164.

58 Pearson HA, Spencer RP, Cornelius EA. Functional asplenia in sickle-cell anemia. N Engl J Med. 1969;281:923-6.

59 Wardrop CA, Dagg JH, Lee FD, Singh H, Dyet JF, Moffat A. Immunological abnormalities in splenic atrophy. Lancet. 1975;2:4-7.

60 Coppo P, Saadoun D, Varet B. Autoimmune manifestations in acquired idiopathic splenic atrophy: a puzzling association. Eur J Intern Med. 2006;17:580-2.

61 Mbanwi AN, Wang C, Geddes K, Philpott DJ, Watts TH. Irreversible splenic atrophy following chronic LCMV infection is associated with compromised immunity in mice. Eur J Immunol. 2017;47:94-106.

62 Di Sabatino A, Rosado MM, Miele L, Capolunghi F, Cazzola P, Biancheri P, et al. Impairment of splenic IgM-memory but not switched-memory B cells in a patient with celiac disease and splenic atrophy. J Allergy Clin Immunol. 2007;120:1461-3.

63 Williams BD, Pussell BA, Lockwood CM, Cotton C. Defective reticuloendothelial system function in rheumatoid arthritis. Lancet. 1979;1:1311-4.

64 Lockwood CM, Worlledge S, Nicholas A, Cotton C, Peters DK. Reversal of impaired splenic function in patients with nephritis or vasculitis (or both) by plasma exchange. $\mathrm{N}$ Engl J Med. 1979;300:524-30.
65 Doe WF, Booth CC, Brown DL. Evidence for complement-binding immune complexes in adult coeliac disease, Crohn's disease, and ulcerative colitis. Lancet. 1973;1:402-3.

66 Konig J, Wells J, Cani PD, García-Ródenas CL, MacDonald T, Mercenier A, et al. Human intestinal barrier function in health and disease. Clin Transl Gastroenterol. 2016;7:e196.

67 Wang F, Zhang P, Jiang H, Cheng S. Gut bacterial translocation contributes to microinflammation in experimental uremia. Dig Dis Sci. 2012;57:2856-62.

68 Khailova L, Baird CH, Rush AA, Barnes C, Wischmeyer PE. Lactobacillus rhamnosus GG treatment improves intestinal permeability and modulates inflammatory response and homeostasis of spleen and colon in experimental model of Pseudomonas aeruginosa pneumonia. Clin Nutr. 2017;36:1549-57.

69 Valdes AM, Walter J, Segal E, Spector TD. Role of the gut microbiota in nutrition and health. BMJ. 2018;361:k2179.

70 Rosado MM, Aranburu A, Scarsella M, Cascioli S, Giorda E, Del Chierico F, et al. Spleen development is modulated by neonatal gut microbiota. Immunol Lett. 2018;199:1-15.

71 Weiberg D, Basic M, Smoczek M, Bode U, Bornemann M, Buettner M. Participation of the spleen in the IgA immune response in the gut. PLoS One. 2018;13:e0205247.

72 Carsetti R, Di Sabatino A, Rosado MM, Cascioli S, Piano Mortari E, Milito C, et al. Lack of gut secretory immunoglobulin $\mathrm{A}$ in memory B-cell dysfunction-associated disorders: a possible gut-spleen axis. Front Immunol. 2020;10:2937.

73 Lewis SM, Williams A, Eisenbarth SC. Structure and function of the immune system in the spleen. Sci Immunol. 2019;4:eaau6085.

74 Corazza GR, Ginaldi L, Zoli G, Frisoni M, Lalli G, Gasbarrini G, et al. Howell-Jolly body counting as a measure of splenic function. A reassessment. Clin Lab Haematol. 1990;12: 269-75.

75 Nakagami Y, Uchino K, Okada H, Suzuki K, Enomoto M, Mizuno S, et al. Potential role of Howell-Jolly bodies in identifying functional hyposplenism: a prospective single-institute study. Int J Hematol. 2020;112:544-52.

76 de Porto AP, Lammers AJ, Bennink RJ, ten Berge IJ, Speelman P, Hoekstra JB. Assessment of splenic function. Eur J Clin Microbiol Infect Dis. 2010;29:1465-73.

77 Corazza GR, Bullen AW, Hall R, Robinson PJ, Losowsky MS. Simple method of assessing splenic function in coeliac disease. Clin Sci. 1981;60:109-13.

78 Lammers AJ, de Porto AP, Bennink RJ, van Leeuwen EM, Biemond BJ, Goslings JC, et al. Hyposplenism: comparison of different methods for determining splenic function. Am J Hematol. 2012;87:484-9.
79 Davies JM, Lewis MP, Wimperis J, Rafi I, Ladhani S, Bolton-Maggs PH. Review of guidelines for the prevention and treatment of infection in patients with an absent or dysfunctional spleen: prepared on behalf of the British committee for standards in haematology by a working party of the haemato-oncology task force. Br J Haematol. 2011;155:308-17.

80 Ferguson A. Hazards of hyposplenism. Br Med J. 1982;285:1375-6.

81 Arnott A, Jones P, Franklin LJ, Spelman D, Leder K, Cheng AC. A registry for patients with asplenia/hyposplenism reduces the risk of infections with encapsulated organisms. Clin Infect Dis. 2018;67:557-61.

82 Di Sabatino A, Lenti MV, Corazza GR. Spleen registry: still a chimera. Clin Infect Dis. 2018; 67:562-3.

83 Ludvigsson JF, Bai JC, Biagi F, Card TR, Ciacci C, Ciclitira PJ, et al. Diagnosis and management of adult coeliac disease: guidelines from the British society of gastroenterology. Gut. 2014;63:1210-28.

84 Pebody RG, Hippisley-Cox J, Harcourt S, Pringle M, Painter M, Smith G. Uptake of pneumococcal polysaccharide vaccine in atrisk populations in England and Wales 19992005. Epidemiol Infect. 2008;136:360-9.

85 Balmer P, Falconer M, McDonald P, Andrews N, Fuller E, Riley C, et al. Immune response to meningococcal serogroup $\mathrm{C}$ conjugate vaccine in asplenic individuals. Infect Immun. 2004;72:332-7.

86 Noh KW, Poland GA, Murray JA. Hepatitis B vaccine nonresponse and celiac disease. Am J Gastroenterol. 2003;98:2289-92.

87 Rosado MM, Gesualdo F, Marcellini V, Di Sabatino A, Corazza GR, Smacchia MP, et al. Preserved antibody levels and loss of memory $B$ cells against pneumococcus and tetanus after splenectomy: tailoring better vaccination strategies. Eur J Immunol. 2013;43:2659-70.

88 Kantsø B, Halkjær SI, Thomsen OØ, Belard E, Gottschalck IB, Jørgensen CS, et al. Immunosuppressive drugs impairs antibody response of the polysaccharide and conjugated pneumococcal vaccines in patients with Crohn's disease. Vaccine. 2015;33:5464-9.

89 Rankine-Mullings AE, Owusu-Ofori S. Prophylactic antibiotics for preventing pneumococcal infection in children with sickle cell disease. Cochrane Database Syst Rev. 2017;10:CD003427.

90 Keenan RD, Boswell T, Milligan DW. Do post-splenectomy patients take prophylactic penicillin? Br J Haematol. 1999;105:509-10.

91 Francino MP. Antibiotics and the human gut microbiome: dysbioses and accumulation of resistances. Front Microbiol. 2016;6:1543.

92 Marild K, Ye W, Lebwohl B, Green PHR, Blaser MJ, Card T, et al. Antibiotic exposure and the development of coeliac disease: a nationwide case-control study. BMC Gastroenterol. 2013;13:109.

93 Theochari NA, Stefanopoulos A, Mylonas KS, Economopoulos KP. Antibiotics exposure and risk of inflammatory bowel disease: a systematic review. Scand J Gastroenterol. 2018;53:1-7. 